\title{
THE USE OF PROCAINE IN ACQUIRED MALIGNANT HYPERTHERMIA \\ IN A PATIENT WITH MALIGNANT MELANOMA METASTATIC TO THE PARATHYROID GLAND: A CASE REPORT
}

\author{
Herman Borden, George J. Hummer, Charles W. Landon, and Jamie Paris
}

AN EXTREMELY RARE CASE is presented of a patient with malignant melanoma metastatic to the parathyroid gland, which apparently stimulated hyperparathyroidism and was associated during surgery with hypertonicity of muscle, hyperpyrexia and hypercalcaemia simulating the circumstances of Malignant Hyperthermia (M.H.). The objective and subjective improvement following intravenous procaine therapy lends credence to the hypothesis that the defect is primarily an effect of calcium on cytoplasmic and/or cellular membrane metabolism. ${ }^{1,2}$

The diagnosis, treatment and mechanisms of M.H. have been elucidated, ${ }^{3,4}$ but the means of pre-operative diagnosis of susceptible patients remains obscure. While familial genetic history ${ }^{5,6}$ and $\mathrm{CPK}$ values ${ }^{7}$ contribute to the diagnosis, a specific test is not available. ${ }^{8}$

The M.H. syndrome is well characterized, ${ }^{9}$ its features being hyperpyrexia, rigidity, arrhythmia, hyperkalaemia, oxygen desaturation, metabolic acidosis, hyperphosphataemia, glucosaemia, hypercalcaemia, myoglobinuria, and elevated serum content of CPK, aldolase, LDH, SGOT. ${ }^{10}$

\section{Case Report}

A 61-year-old Caucasian male was admitted for the third and final time for complaint of continued pain in the region of the lower back and left anterior chest wall, aggravated by activity in the upright position. Four months previously he had undergone removal of a malignant melanoma of the skin of the left upper back, together with left axillary dissection. One left axillary lymph node was involved in metastatic disease. Biopsy of left posterior iliac crest revealed presence of Paget's disease of bone. X-ray studies showed degenerative arthritic changes of dorsal and lumbar spine. Isotope bone scan suggested osteoblastic activity of the first and second lumbar vertebrae. There was a history of peptic ulcer with three episodes of gastro-intestinal bleeding within the preceding ten years.

The patient was acutely ill with a combination of factors which made therapy difficult. In addition to his pain, he showed irritability, disorientation, hypertonicity,

Herman Borden, M.D., Division of Anesthesiology, St. John's Hospital, Santa Monica, California; Clinical Instructor, Anesthesiology, University of California at Los Angeles.

George J. Hummer, M.D., Department of Pathology, St. John's Hospital, Santa Monica, California; Associate Clinical Professor of Pathology, University of California, Los Angeles.

Charles W. Landon, M.D., F.A.C.S, Department of Surgery, St. John's Hospital, Santa Monica, Ca.; Assistant Clinical Professor of Surgery at the University of California at Los Angeles; Attending Surgeon at V.A. Wadsworth Hospital, Los Angeles.

Jamie Paris, M.D., F.A.C.P., Department of Internal Medicine, St. John's Hospital, Santa Monica, Ca.; Assistant Clinical Professor of Medicine at the University of California, Los Angeles. 


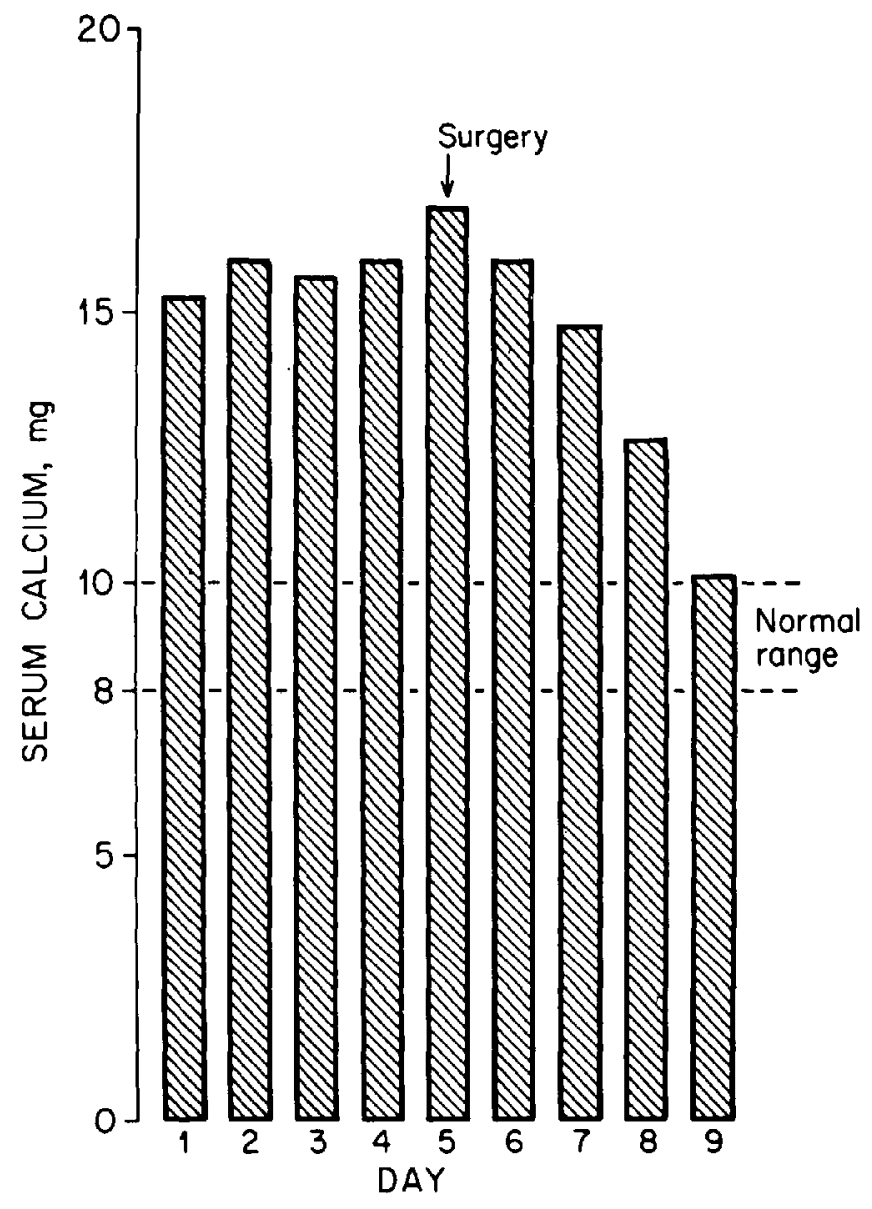

Figune 1. Serum calcium values before, during, and after operation.

hyperthermia to $38.8^{\circ} \mathrm{C}$, acidosis, hypercalcaemia (Figure 1), elevated LDH and declining serum potassium.

He became dyspnoeic and developed atrial fibrillation with tachycardia of $170 / \mathrm{min}$ (Figure 2). A variety of agents and approaches were used to treat him, including intravenous fluids containing sodium and potassium, intravenous mithramycin, and furosemide. Neutraphos was given orally and by nasogastric tube. Electrical cardio-version was performed using 250 watt per second D.C. countershock in conjunction with quinidine administration. Elevation of blood pressure as high as $240 / 130 \mathrm{~mm} \mathrm{Hg}$ occurred.

He returned to normal sinus rhythm and finally to a normal calcium level. Serum calcium gradually returned to higher levels, with a coincident rise of phosphate. Calcium and parathormone serum levels supported a diagnosis of hyperparathyroidism (Figure 3).

Despite the high risks, surgical exploration of the neck was scheduled, for treatment of the hyper-functioning parathyroid lesion. A parathyroid gland was removed, which on sectioning revealed presence of metastatic malignant melanoma 


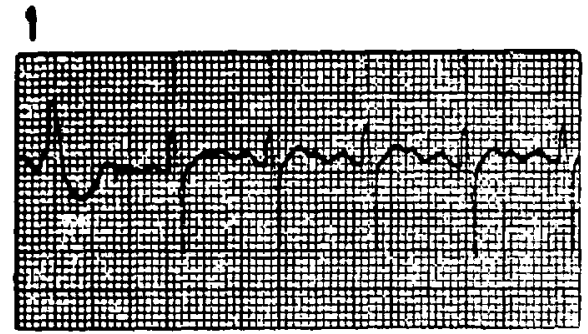

SINUS TACHYCARDIA.

OCCASIONAL VENTRICULAR

PREMATURE BEATS ARE SEEN.

RATE: $110 / \mathrm{min}$

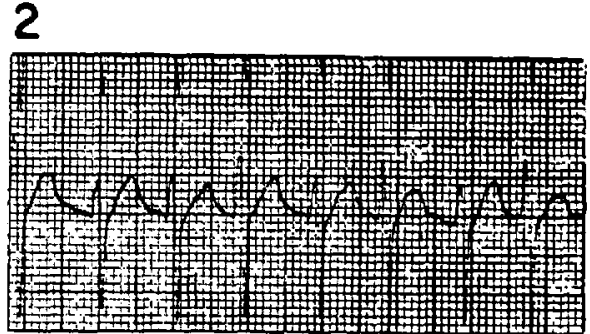

ATRIAL FIBRILLATION WITH AN AVERAGE VENTRICULAR RATE OF $180 / \mathrm{min}$.

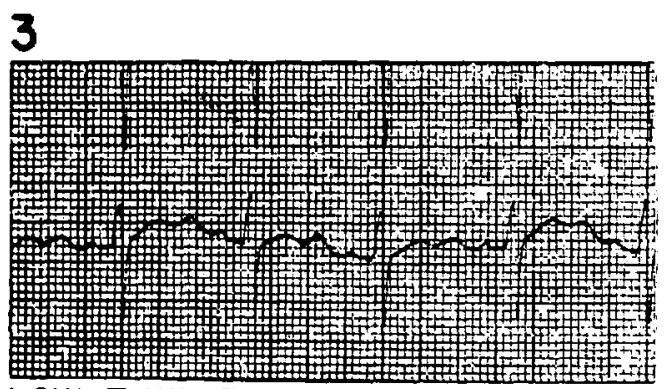

LOW T WAVE AMPLITUDE WITH PROLONGATION OF THE QT INTERVAL, AND PROMINENT U WAVES

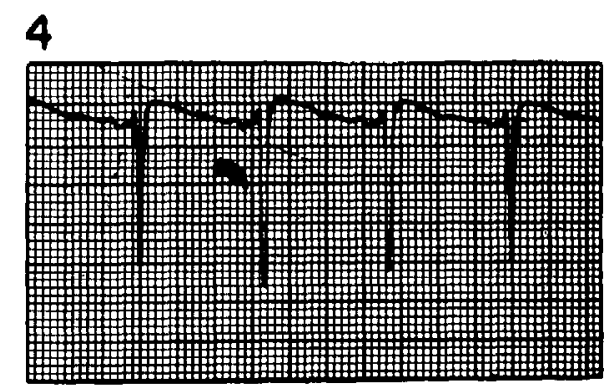

RATE: $90 \mathrm{~min}$

Figune 2. Electrocardiographic changes prior to and following D.C. countershock.

(Figure 4). Two separate metastatic foci were also determined to be present in two biopsy specimens of thyroid tissue.

Operative and post-operative rectal temperature of $35^{\circ} \mathrm{C}$ was maintained with the aid of a K-Thermia extra-corporeal cooling mattress.

Anaesthetic management consisted of sodium thiamylal induction with orotracheal intubation following pancuronium bromide $(6 \mathrm{mg})$. Ethrane and oxygen were administered. Pulse rate decreased fom 120 to 100 per minute with sinus rhythm. An 0.4 per cent procaine solution was administered rapidly, $800 \mathrm{mg}$ being given in the first hour, followed by $400 \mathrm{mg} / \mathrm{hr}$ in the recovery room. Procaine was discontinued on the first post-operative day.

In the recovery room the patient was lucid, coherent and conversant with family. $\mathrm{He}$ remained normothermic. Postoperative serum calcium values are presented in Figure 1.

After the operation the patient's condition worsened and he died four days after the surgical exploration of the neck. Permission for post-morten examination was refused.

\section{Discussion}

Metastasis of malignant tumor to parathyroid gland is in itself a rarity worthy of note. Our search of the medical literature reveals only one previously recorded case, 


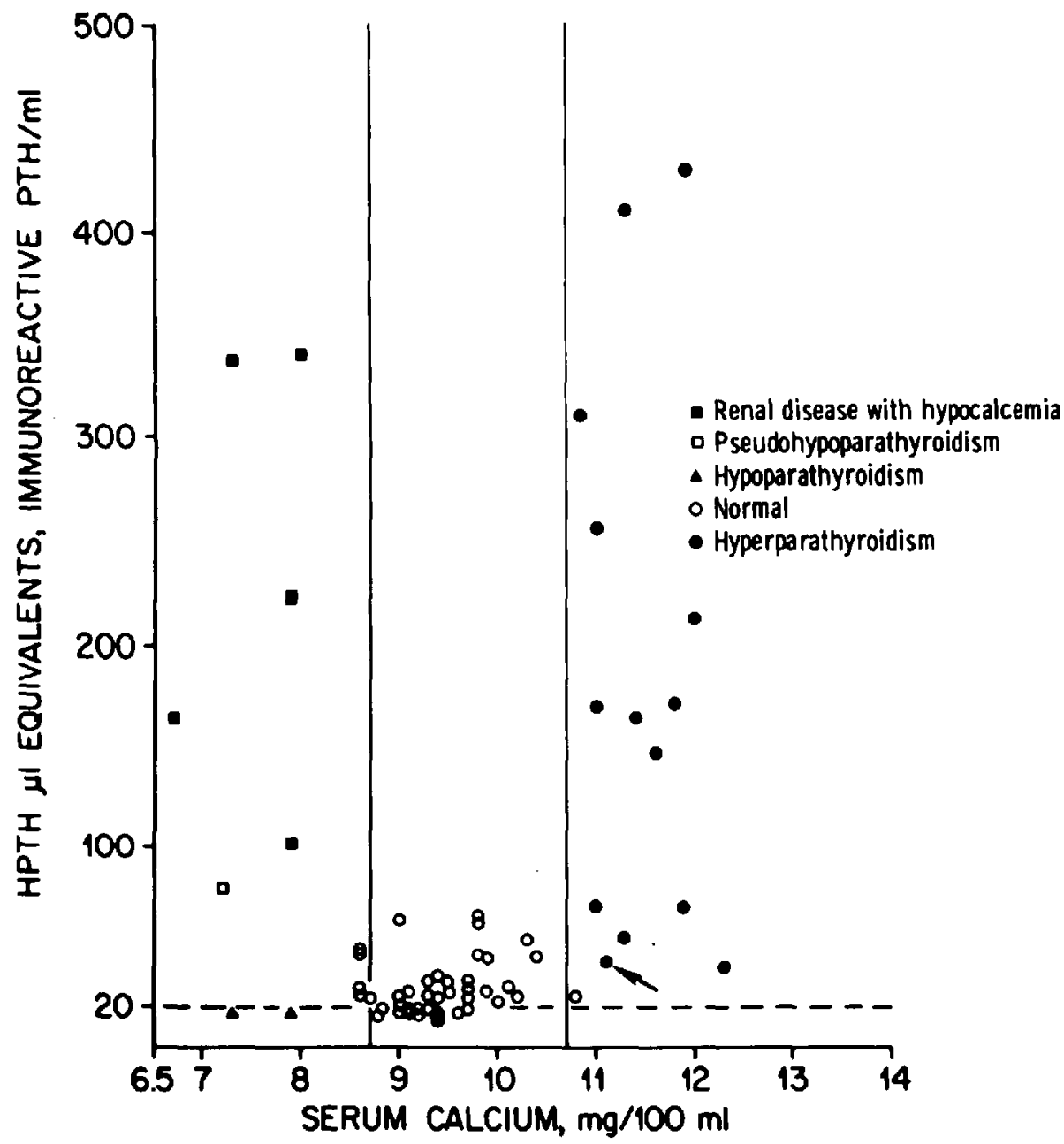

Figune 3. Parathomone assay.

an instance of carcinoma of breast metastatic to parathyroid. ${ }^{11}$ In that instance, hyperpyrexia was not a clinical feature.

Evidence substantiates that the primary abnormality responsible for the M.H. syndrome lies within the muscle. ${ }^{12-1.4}$ A triggering substance releases calcium from defective calcium-storing membranes of the muscle cell ${ }^{15}$ to both the extracellular fluid and intracellular myoplasm. There is a fall in muscle calcium and rise in serum calcium. ${ }^{16,17}$

Total calcium content of both human and porcine malignant hyperthermic susceptible (MHS) skeletal muscle is significantly less than normal. Some organelle such as sarcoplasmic reticulum stores less than normal amounts of calcium in MHS muscle. ${ }^{16}$

So-called "caffeine rigor" 18 in muscle described by Harrison is associated with enhanced release and depression of or binding of calcium ions $\mathrm{s}^{19,20}$ by the sarcoplasmic reticulum. ${ }^{21}$ Halothane apparently inhibits calcium uptake into the sarco- 


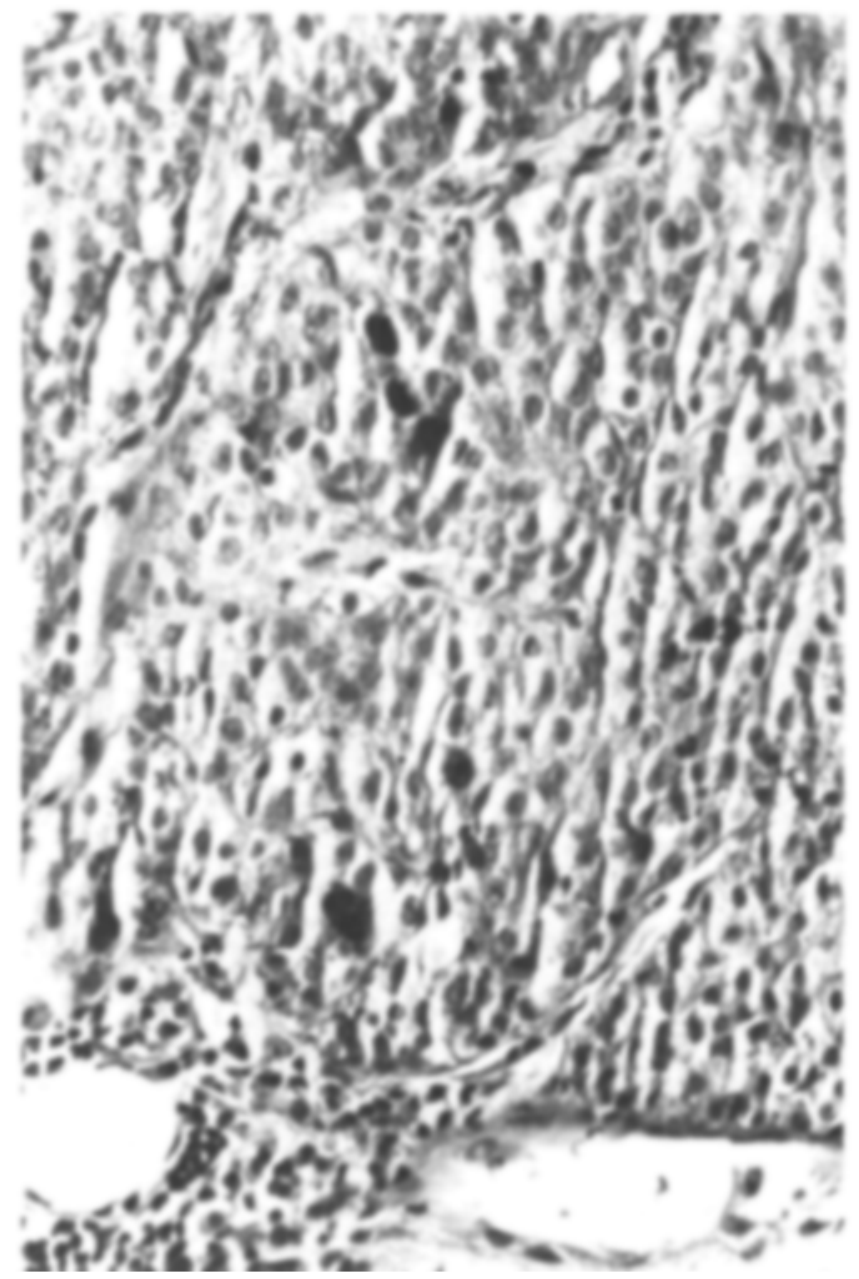

Figure 4. Photomicrograph of parathyroid gland with melanotic implants. $\times 400$.

plasmic reticulum. ${ }^{22}$ In experiments utilizing rat liver and heart muscle of a number of species, there appears to be a relationship between inhibition of NADH dehydrogenase by halothan $\mathrm{e}^{23}$ and other volatile anaesthetics, and a decrease in the rate of accumulation of calcium by isolated mitochondria. ${ }^{24}$

If malignant hyperthermia is characterized by a defect in calcium-storing membranes, drugs which lower myoplasmic calcium should prove of therapeutic benefit. Such is the case with procaine. ${ }^{18}$ Porcine experimentation has shown that procaine blocks the induction of malignant hyperthermia by both halothane ${ }^{25}$ and succinylcholine. ${ }^{2 \mathrm{~B}}$

While investigating the biochemical aspects of porcine M.H. syndrome, Mitchell and Heffron ${ }^{27}$ found that once the clinical signs had become apparent, procaine did not reverse the condition. The circulating procaine levels differed from those reported by Hall and Lister who stated that after an injection of procaine $0.4 \mathrm{gm}$, in man, the blood level was only $0.4 \mathrm{mM} .{ }^{28}$ A level of $5 \mathrm{mM}$ is necessary to reverse the 
muscle rigidity, fever and metabolic acidosis, according to Moulds and Denborough. ${ }^{29}$

Clarke and Ellis have challenged the use of procaine as the drug of first choice in patients with M.H. ${ }^{30}$ They maintain it should be reserved for those in whom other measures such as dexamethasone have failed to prevent increase in temperature or increasing rigor. In some patients, they contend, procaine may exacerbate contracture.

The pre-treatment with curare ${ }^{31}$ prevents only the triggering action of succinylcholine. This agent decreases myoplasmic calcum by accelerating active calcium uptake into the sarcoplasmic reticulum.

In a case presentation by Brebner and Jozefowicz, ${ }^{32}$ it was suggested that local anaesthetics should be avoided in the non-rigid type of hyperthermia since the primary defect does not appear to be an error in calcium metabolism per se.

Anderson has postulated a relationship between the concentration of intracellular cyclic AMP and calcium ions. An increase in cyclic AMP concentration stimulates calcium accumulation in the cell with reduced calcium concentration in the vicinity of the contractile elements. This reduced calcium ion concentration would interfere with the interaction of contractile elements resulting in smooth muscle relaxation. ${ }^{33}$

Hyperpyroxia ocurring both during and after operation due to M.H., to lymphosarcoma with a pheochromocytoma, to thyrotoxicosis, and to septic shock are discussed by Schweizer, Howland, Ryan and Goldiner ${ }^{34}$ Our case further supports the premise that any factor which elevates myoplasmic calcium will tend to induce a malignant hyperthermia-like reaction.

Orotracheal intubation was performed with relaxation provided by pancuronium bromide. Smith and Petruscak have described a case of ventricular fibrillation following administration of succinylcholine ${ }^{35}$ in a hypercalcaemic digitalized patient. Arrhythmias produced by hypercalcaemia include bradycardia and asystole. Intravenous calcium shortens the QT interval and increases the QRS duration. The combination of decreased conduction velocity and shortened refractory period could facilitate re-entry and the occurrence of ventricular ectopic beats. ${ }^{36}$ Calcium, much as digitalis, inhibits adenosine triphosphatase (ATPase) in blocking the active transport of sodium and potassium. Direct current countershock was employed in lieu of chemical conversion because of the hypercalcaemia and hypokalaemia which both potentiate the action of digitalis.

Surface cooling was employed preoperatively and during operation for maintenance of body temperature. Following the administration of procaine, cooling was not required. This effect has previously been desecribed by Beldavs, Small, Cooper and Britt. ${ }^{37}$

Mithramycin, a drug useful in treating hypercalcaemia associated with neoplastic disease, is believed to reduce calcium concentrations by acting directly on bone. ${ }^{38}$ With this chemotherapeutic agent, serum calcium may not fall for 24 to 48 hours, but once calcium lowering is achieved, the effect may last for up to three weeks. Serum calcium levels of our patient are displayed in Figure 1.

It can be postulated that the mechanism by which succinylcholine, ${ }^{39}$ severe exercise, halothane, ${ }^{40}$ and possibly hyperparathyroidism initiate the syndrome of M.H. is by defective reticular calcium binding. This allows persistence of a high 
concentration of calcium ions in the sarcoplasm, ${ }^{41}$ resulting in continuous rigor, "runaway" glycolysis and profound acidosis.

\section{SUMMARY}

The use of intravenous procaine in the treatment of hyperpyrexia in a patient with hyperparathyroidism has not been previously reported. A case of metastatic malignant melanoma precipitating the syndrome of hypertonicity of muscle, hyperpyrexia, acidemia, hypercalcemia and elevated serum parathormone levels is presented.

Mithramycin was used in an attempt to reduce elevated serum calcium concentrations. The use of intravenous procaine in "caffeine rigor" and malignant hyperthermia due to succinylcholine and halothane formed the basis for its trial in this case.

The relationship between cyclic AMP and calcium ions is discussed in postulating a mechanism of procaine action.

\section{RÉSUMÉ}

Le mélanome malin métastatique de la glande parathyroïde n'a pas été antérieurement rapporté. Un cas de mélanome malin métastatique précipitant le syndrome d'hypertonicité musculaire avec hyperthermie, acidémie, hypercalcémie et élévation de la parathormone sérique est présenté.

L'emploi de procaine intraveineuse dans le "caffeine rigor" et dans l'hyperthermie maligne due à la succinylcholine et à l'halothane explique son utilisation dans ce cas d'hyperthyroïdisme. La mithramycine a été utilisée dans le but de réduire les concentrations sériques élevées de calcium.

\section{REFERENCES}

1. Weber, A., Herz, R., \& Reiss, I. The requirement of Ca for the contraction of isolated actomyosin systems. Proc. Roy. Soc. 160: 489-501 (1964).

2. Winegrad, S. The location of muscle calcium with respect to the myofibrils. J. Gen. Physiol. 48: 997-1002 (1965).

3. Bнitт, B.A. Recent advances in malignant hyperthermia. Anesth. Analg. Curr. Res. 51: 841 (1972).

4. RYAN, J.F. The early treatment of malignant hyperthermia. International symposium on malignant hyperthermia, Springfield: Thomas, p. 430 (1973).

5. Bhitt, B.A., Locher, W.G., \& KAlow, W. Hereditary aspects of malignant hyperthermia. Canad. Anaesth. Soc. J. 16:89 (1969).

6. Denbonough, M.A., King, J.O., \& FAPF, P.W. Inheritance of malignant hyperpyrexia. Lancet 1: 365-70 (1972).

7. Is AacS, H. \& BAnLow, M.B. The genetic background to malignant hyperpyrexia revealed by serum creatine phosphokinase estimations in asymptomatic relatives. Brit. J. Anaesth. 42: 1077-1084 (1970).

8. Aldrete, J.A., Padfield, A., Solomon, C.C., et al. Possible predictive tests for malignant hyperthermia during anesthesia. J.A.M.A. 215: 1465-1469 (1971).

9. Britt, B.A. \& Kalow, W. Malignant hyperthermia: a statistical review. Canad. Anaesth. Soc. J. 17: 293-315 (1970).

10. Denbonouch, M.A., Hudson, M.C., Forster, J.F.A., et al. Biochemical changes in malignant hyperpyrexia. Lancet 1: 1137-1138 (1970).

11. Woolner, Keating, \& Black. Primary hyperparathyroidism and metastatic breast carcinoma: a case in which breast cancer metastasized to a parathyroid adenoma. Cancer 11: 975 (1958).

12. Denborough, M.A., Kinc, J.O., Ebeling, P., et al. Myopathy and malignant hyperpyrexia. Lancet 1: 1138-1140 (1970).

13. Kalow, W., Bhitt, B.A., Terreau, M.E., \& Haist, C. Metabolic error of muscle metabolism after recovery from malignant hyperthernia. Lancet 2: 895 (1970). 
14. Thonpe, W. \& Seeman, P. Drug-induced contracture of muscle. In International Symposium on Malignant Hyperthermia. Springfield: Thomas, p. 152 (1973).

15. Kalow, W., Britt, B.A., Terreau, M.E., et al. Metabolic error of muscle metabolism after recovery from malignant hyperthermia. Lancet 2: 895-898 (1970).

16. Britt, B.A., Endrenyi, L., Barclay, R.L., \& Cadman, D.L. Total calcium content of skeletal muscle isolated from humans and pigs susceptible to malignant hyperthermia. Brit. J. Anaesth. 47: 647-649 (1975).

17. "Physicians tend to miss malignant hyperthermia," J.A.M.A. 235: 238 (1976).

18. Thorpe, W.R. \& SeEman, P. The site of action of caffeine and procaine in skeletal muscle. J. Pharm. Exp. Ther. 179:324-330 (1971).

19. Hahrison, G.G., Biebuxck, J.F., Terblanche, J., et al. Hyperpyrexia during anaesthesia. Brit. Med. J. 3: 594-595 (1968)

20. Harrison, G.G., Saunders, S.J., Biebuyck, J.F., et al. Anaesthetic-induced malignant hyperpyrexia and a method for its prediction. Brit. J. Anaesth. 41: 844-854 (1969).

21. Devine, C.E. Sarcoplasmic reticulum and excitation contraction coupling in mammalian smooth muscles. J. Cell. Biol, 52: 690-718 (1972).

22. Harrison, G.G. Anaesthetic-induced malignant hyperpyrexia: a suggested method of treatment. Brit. Med. J. 3: 454-456 (1971).

23. Millen, R.N. \& Hunter, F.E. Is halothane a true uncoupler of oxidative phosphorylation? Anesthesiology 34: 256-261 (1971).

24. Loyten, A., Christiansen, R.O., Steensland, H., et al. Energy-linked ion translocation in submitochondrial particles. I. $\mathrm{Ca}++$ accumulation in submitochondrial particles. J. Biol. Chem. 244: 4422-4427 (1969).

25. Woolf, N., Hall, L., Thorne, C., et al. Serum creatine phosphokinase levels in pigs reacting abnormally to halogenated anaesthetics. Brit. Med. J. 3: 386-387 (1970).

26. HaLl, L.W., WoOLF, N., BradLEY, J.W.P., et al. Unusual reaction to suxamethonium chloride. Brit. Med. J. 4: 1305 (1966).

27. Mitchel. , G. \& Heffron, J.J.A. Procaine in porcine malignant hyperthermia. Brit. J. Anaesth. 47:667 (1975).

28. HaLl, G.M. \& Lister, D. Procaine and malignant hyperthermia. Lancet $1: 208$ (1974).

29. Moulds, R.F.W. \& Denbonough, M.A. Procaine in malignant hyperthermia. Brit. Med. J. 4: $526(1972)$.

30. Clarke, I.M.C. \& Ellis, F.R. An evaluation of procaine in the treatment of malignant hyperpyrexia. Brit. J. Anaesth. 47: 17-20 (1975).

31 Harrison, G.G. The effect of procaine and curare on the initiation of anaesthetic-induced malignant hyperpyrexia. International Symposium on Malignant Hyperthermia. Springfield: Thomas, p. 271 (1973).

32. Brebner, J. \& Jozefowicz, J.A. Procainamide therapy of malignant hyperthermia: a case report. Canad. Anaesth. Soc. J. 21 : 104-105 (1974).

33. ANDERSon, R. Effect of halothane, chloroform and fluroxene on pigeon heart mitochondrial electron transfer and calcium uptake. Fifth International Congress on Pharmacology (1972).

34. Schweizer, O., Howland, W.S., RYan, G.M., \& Goldiner, P.L. Hyperpyrexia in the operative and immediate postoperative period. Anaesth. Analg. 50: 906 (1971).

35. Simth, R.B. \& Petruscak, J. Succinylcholine, digitalis and hypercalcemia. Anaesth. Analg. 51:204-205 (1972)

36. KATZ, R.L. \& Biggen, T.T. JR. Cardiac arrhythmias during anesthesia and operation. Anesthesiology 33: 193-213 (1970).

37. Beldavs, J., SMall, V., Cooper, D.A., et al. Post-operative malignant hyperthermia: a case report. Canad. Anaesth. Soc. J. 18: 202-212 (1971).

38. Singen, F.R., et al. Mithramycin treatment of intractable hypercalcemia due to parathyroid carcinoma. New England J. of Med. 28.3: 634 (1970).

39. Gondon, R.A., Britr, B.A., \& Kalow, W. Rhabdomyolysis and hyperpyrexia in children after administration of succinylcholine, p. 30 . Biochemical features of malignant hyperthermia in Landrace pigs, p. 287. International Symposium on Malignant Hyperthermia. Springfield: Thomas (1973).

40. Britt, B.A., Endrenyi, L., Cadman, D.L., Ho, M.F., \& Fung, H.Y-K. Porcine malignant hyperthermia - effect of halothane on mitochondrial respiration and calcium accumulation. Anesthesiology 42: 292 (1975).

41. Martonosi, A. \& Feretos, R. Sarcoplasmic reticulum. I: The uptake of Ca ++ by sarcoplasmic reticlum fragments. J. Biol. Chem. 239: 648 ( 1964 ). 